\title{
Serodiagnosis of Trichomonas vaginalis infection by the indirect fluorescent antibody test
}

\author{
P. R. MASON \\ From the Department of Medical Microbiology, University of Zimbabwe Rhodesia, PO Box MP 167, \\ Mount Pleasant, Salisbury, Zimbabwe Rhodesia
}

SUMMARY The indirect fluorescent antibody test was used to detect antibodies to Trichomonas vaginalis in 200 antenatal patients. A total of $104(52 \%)$ gave a positive reaction with antigen prepared from cultures of trichomonas isolated from seven of the patients. Antitrichomonal antibody was detected at a $1 / 4$ dilution in $90 \%$ of patients with proven trichomoniasis, while the highest dilution at which antibody was detected was $1 / 32$. IgG rather than IgM appeared to be the antibody class involved. Of those patients with no demonstrable trichomonal infection, $17 \%$ gave positive reactions at $1 / 4$ dilution, while $64 \%$ had no demonstrable antibody. One of 30 children under 11 years of age gave a positive reaction.

Infection of the urogenital tract of both men and women by Trichomonas vaginalis is common, and while many cases are asymptomatic, trichomonal vaginitis and urethritis are frequently encountered distressing conditions. Moreover, asymptomatic cases may act as a reservoir for venereal transmission of the disease. With the introduction of metronidazole simple and effective treatment of infections became possible (Forgan, 1972), and the major problem in control of the disease remains the accuracy of diagnosis (Hughes et al., 1966). At present diagnosis depends on the microscopic demonstration of the parasite in wet smears, stained smears, or culture media, of which many have been described. The effectiveness of these methods is variable and depends on both the type of specimen taken (Hughes et al., 1966) and the processing of the specimen in the laboratory (Mason et al., 1976). Serological techniques therefore seem to be advantageous for diagnosing infections.

Antibodies to trichomonas are found in the serum of infected women, but the titres are in general low (Honigberg, 1972), and Ackers et al. (1975) considered their slow appearance to limit their value in the diagnosis of active disease. Attempts have been made to demonstrate antibodies in vaginal secretions but without success. Antitrichomonal IgA was found to be absent in the vaginal fluid of

Received for publication 28 June 1979 many patients with active $T$. vaginalis infections, while it was present in $42 \%$ of women with no evidence of existing trichomoniasis (Ackers et al., 1975).

Direct immunofluorescent studies (Chipperfield and Evans, 1972) have shown that IgM is present, particularly around blood vessels, in addition to IgA in the endocervix of patients with trichomoniasis, suggesting that serum antibodies may in fact be of diagnostic value. The present study investigates serum antibodies in patients with subclinical trichomonal infection.

\section{Material and methods}

\section{ANTIGEN}

$T$. vaginalis, isolated from women attending an antenatal clinic, was cultured in agarless Diamond's (1957) medium containing penicillin (1000 units $/ \mathrm{ml})$, streptomycin $(500 \mu \mathrm{g} / \mathrm{ml})$, and nystatin $(250 \mu \mathrm{g} / \mathrm{ml})$. Cultures were kept under hydrogen at $37^{\circ} \mathrm{C}$ and were passaged every 48-72 hours. After the first three passages nystatin was omitted from the medium, and antigen was prepared from organisms which had had at least six passages.

For antigen preparation 48-hour cultures were centrifuged. The organisms were washed twice with phosphate buffered saline (PBS) and suspended in $10 \%$ formalin in PBS for 5 minutes. The cells were washed twice more with PBS and resuspended in PBS to about $1.5 \times 10^{6}$ organisms $/ \mathrm{ml}$. Drops of this 
suspension were put into wells on PTFE-coated slides and air-dried.

Antigen slides were made using single cultures, that is, organisms cultured from one patient ('spantigen'), and a mixture of seven cultures ('coantigen'), and were stored at $-20^{\circ} \mathrm{C}$ before use.

SERA

\section{Known positives}

These were obtained from the seven patients from whom $T$. vaginalis was isolated and used for antigen preparation. They thus represent the homologous sera to each sp-antigen.

\section{Presumed negatives}

Thirty sera were obtained from children aged 10 years or less. The sera were originally taken for viral investigations and the children were not suspected of having had contact with trichomonads.

\section{Unknown sera}

A further 193 sera were obtained from women attending the antenatal clinic. High vaginal swabs were also taken from these patients, inoculated into Powell's (1936) medium, and examined three times in the subsequent $\mathbf{7 2}$ hours for motile trichomonads. None of the women complained of discharge or irritation, and none showed clinical signs of acute trichomoniasis. Details of the gynaecological history of these patients will be published elsewhere (Mason and Brown, in preparation).

All sera were inactivated at $56^{\circ} \mathrm{C}$ for 30 minutes and stored frozen before use.

\section{TESTS}

Standard indirect fluorescent antibody (IFA) procedures were used. Undiluted serum was incubated on the antigen spots for 30 minutes at $37^{\circ} \mathrm{C}$. Slides were washed with PBS $(2 \times 15 \mathrm{~min})$, air dried, and reincubated for 30 minutes with fluorescin-labelled immunoglobulin (Wellcome) at 1/25 dilution and rhodamine (Difco) at 1/10 dilution on the antigen spots. Slides were washed in PBS $(3 \times 10 \mathrm{~min})$, mounted in buffered glycerol, and examined with an Olympus Vanox microscope with incident UV illumination from a 200 watt bulb at a total magnification of $200 \times$.

The seven known positive sera were tested undiluted with each sp-antigen and with the coantigen. The 30 presumed negative sera were tested undiluted with co-antigen and with sp-antigen 193. The unknown sera were tested undiluted with the co-antigen and sp-antigen 193, and doubling dilutions in PBS of all positive sera (including the seven known positives) were tested against co-antigen and against one of the seven sp-antigens selected at random.

In order to determine the class of antibody involved, 30 known positive sera, with titres ranging from $1 / 2$ to $1 / 16$ with non-specific immunoglobulin, were tested at a $1 / 2$ dilution with fluorescin-labelled IgM and IgG (Miles Labs, Cape Town).

Eight negative sera were used as controls, and all sera were tested using the co-antigen.

\section{Results}

\section{FLUORESCENCE}

Variation in the staining reactions of organisms, even those in the same well, were evident with all combinations of antigen and serum. Three types of reaction were noted:

(a) Negative, characterised by a lack of fluorescence, organisms staining orange/red with rhodamine.

(b) Marginal fluorescence (MF), characterised by a distinct band of fluorescence around the perimeter of the organism and including the flagellae. The cell body stained orange/red with rhodamine.

(c) General fluorescence (GF), characterised by fluorescence over the whole body of the organism, but with no distinct perimeter. Flagellae were often absent, or at least could not be seen with either UV or normal illumination.

Because of its association with non-flagellated cells, GF was regarded as a non-specific reaction to the dead or degenerate organisms which were always present in the cultures. The presence of MF in at least $50 \%$ of flagellated cells was the criterion used to describe a reaction as positive. An incomplete band of faint fluorescence around the organism was recorded as a weak positive.

Table 1 Reactions between sp- and co-antigens and undiluted homologous sera

\begin{tabular}{|c|c|c|c|c|c|c|c|c|}
\hline & \multicolumn{7}{|c|}{ SP-antigen } & \multirow[t]{2}{*}{ Co-antigen } \\
\hline Serun & 46 & 175 & 180 & 193 & 198 & 202 & 213 & \\
\hline 46 & & & + & + & $+w$ & + & + & + \\
\hline 175 & & & & + & + & + & + & + \\
\hline 180 & + & 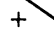 & & & + & + & + & + \\
\hline 193 & + & + & & & & + & + & + \\
\hline 198 & + & $+w$ & + & T & & & + & + \\
\hline 202 & + & + & + & + & & & + & + \\
\hline 213 & + & + & + & + & - & & & + \\
\hline
\end{tabular}

+ , positive reaction; + w, weak positive reaction; - , negative reaction. 


\section{KNOWN POSITIVES}

Of the 49 combinations of sp-antigens with their sera, $46(94 \%)$ gave positive reactions (Table 1$)$.

Sp-antigens 198 and 202 gave negative reactions with serum 213, while sp-antigen 202 gave a negative reaction with its homologous serum. Four antigens, $46,180,193$, and 213, gave strong positive results with all seven sera, as did the co-antigen.

\section{PRESUMED NEGATIVES}

Only one of the 30 children's sera (a girl aged 10 years) gave a positive reaction with the co-antigen, while two others (a girl aged 7 and a boy aged 10 years) also gave weak reactions with sp-antigen 193. The other $27 \operatorname{sera}(90 \%)$ were negative with both antigens.

\section{UNKNOWN SERA}

Of the 200 sera collected from antenatal patients, $104(52 \%)$ gave a positive reaction with co-antigen when used undiluted. Table 2 shows the distribution of titres of antibody found. Examination of vaginal swabs from the same patients revealed $52(26 \%)$ with $T$. vaginalis infections, and although serum antibodies to $T$. vaginalis could not be found in four of these patients, $90 \%$ had antibodies detectable at a $1 / 4$ dilution. In patients in whom trichomonads could not be demonstrated microscopically, only $17 \%$ had antibodies detectable at a 1/4 dilution and $64 \%$ had no demonstrable antibody in undiluted serum (Fig. 1).

Table 2 T. vaginalis antibody titres in 200 antenatal patients

\begin{tabular}{|c|c|c|c|c|c|c|c|c|}
\hline & \multirow{2}{*}{$\begin{array}{l}\text { Nega- } \\
\text { tive }\end{array}$} & \multicolumn{6}{|c|}{ Reciprocal titres } & \multirow{2}{*}{$\begin{array}{l}\text { Total } \\
\text { positive }\end{array}$} \\
\hline & & 1 & 2 & 4 & 8 & 16 & 32 & \\
\hline $\begin{array}{l}\text { Number } \\
\%\end{array}$ & $\begin{array}{l}96 \\
48\end{array}$ & $\begin{array}{r}12 \\
6\end{array}$ & $\begin{array}{l}19 \\
9 \cdot 5\end{array}$ & $\begin{array}{l}30 \\
15\end{array}$ & $\begin{array}{l}25 \\
12 \cdot 5\end{array}$ & $\begin{array}{l}13 \\
6.5\end{array}$ & $\begin{array}{l}5 \\
2 \cdot 5\end{array}$ & $\begin{array}{r}104 \\
52\end{array}$ \\
\hline
\end{tabular}

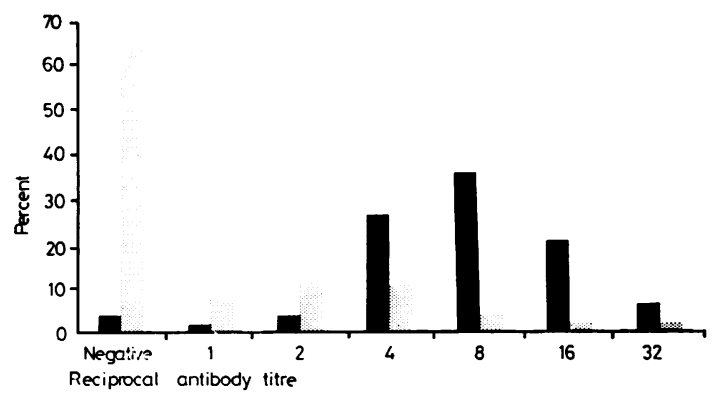

Fig. 1 Distribution of antibody titres in 200 antenatal patients. Black bars represent patients with proven trichomonal infection; shaded bars, patients from whom T. vaginalis was not isolated.

\section{COMPARISON OF ANTIGENS}

Three of the 104 sera positive with co-antigen were found to be negative using sp-antigen 193. The correlation between titres assessed using co-antigen and the seven sp-antigens was generally good (Fig. 2), differences of more than one dilution being rare. In $10 \%$ of cases, the sp-antigen gave a higher titre, and in $22 \%$ a lower titre, than the co-antigen.

\section{ANTIBODY CLASS}

Only eight of 30 positive sera gave a positive reaction at a $1 / 2$ dilution with IgM, and in five of these the reaction was recorded as 'weak'. Twentynine sera gave a positive reaction with IgG. Table 3 compares the results found using IgM and IgG with the non-specific immunoglobulin. All eight negative sera were negative with IgG and IgM.

Table 3 Comparison of $\operatorname{Ig} G$ and IgM antibodies in positive sera

\begin{tabular}{|c|c|c|c|}
\hline \multirow{2}{*}{$\begin{array}{l}\text { Antibody } \\
\text { titre }\end{array}$} & \multicolumn{3}{|c|}{ Number of sera giving a positive reaction at $1 / 2$ dilution } \\
\hline & $\begin{array}{l}\text { Non-specific } \\
\text { immunoglobulin }\end{array}$ & $\operatorname{Ig} G$ & $\operatorname{Ig} M$ \\
\hline $\begin{array}{r}2 \\
4 \\
8 \\
16\end{array}$ & $\begin{array}{r}7 \\
10 \\
11 \\
2\end{array}$ & $\begin{array}{r}6 \\
10 \\
11 \\
2\end{array}$ & $\begin{array}{l}0 \\
4 \\
4 \\
0\end{array}$ \\
\hline Total & 30 & 29 & 8 \\
\hline
\end{tabular}

*Using non-specific immunoglobulin.

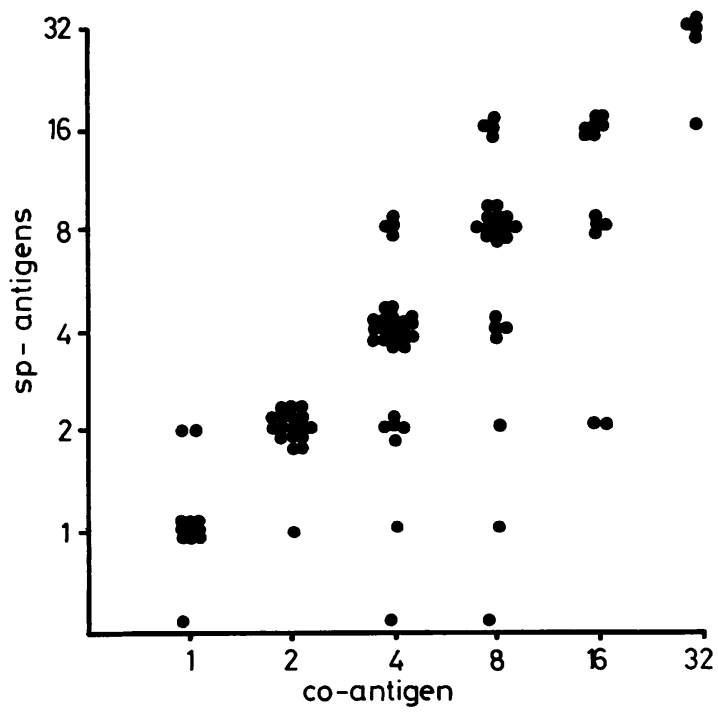

Fig. 2 Comparison of antibody titres obtained using sp-antigens and co-antigen. 


\section{Discussion}

The major difficulty with the IFA test is the interpretation of the results. Kramar and Kucera (1966), in their study of IFA reactions in trichomoniasis, described two kinds of fluorescence which can be equated to the GF and MF described above. They, however, interpreted GF as indicating the presence of antibody and MF as being a reaction to old organisms, and they therefore disregarded the latter. From the present studies, however, MF was almost always observed with known positives, while GF was not.

With the children's sera, several showed GF while only one showed strong MF. This indicated that MF was a better indicator of the presence of antibody in the serum, especially as most cells showing GF appeared to be without flagellae and were probably degenerate organisms.

There was a good correlation between tests using sp-antigen 193 and co-antigen, $97 \%$ of sera positive by the latter being also positive by the former. Antibody titres in $68 \%$ of cases were equal using co-antigen and sp-antigen; in $10 \%$ of cases sp-antigen gave a higher titre, and in $22 \%$ of cases a lower titre, than the co-antigen. According to previous workers (reviewed by Jirovec and Petrů (1968)), there are serotypes of $T$. vaginalis, and the use of a combined antigen would be expected, as shown, to improve the reliability and sensitivity of the test.

With the co-antigen, only one of 30 sera from prepubescent children was positive. $T$. vaginalis infection of children has been recorded, though usually in neonates (Al-Salihi et al., 1974). Heller et al. (1969) found only one case of trichomonal infection in 50 children with vulvovaginitis, and this was in a 13-year-old. The positive serum in the present study came from a 10-year-old girl, and the possibility of contact with trichomonads could not be discounted. However, this child was also the only one of the group with a positive $\mathrm{HBs} \mathrm{Ag}$ test, and cross-reactions may have occurred.

The absence of MF in all but one of 30 presumed negative sera, and the presence of MF in $96 \%$ of known infections, indicates that the test is reliable, particularly in comparison with other serological tests for trichomoniasis (see Ackers et al., 1975).

As found by Kramar and Kucera (1966), antibody titres were low, rarely exceeding $1 / 16$. Of the 52 infections diagnosed microscopically, $46(88 \%)$ had an antibody titre of at least $1 / 4$, while only $26 / 148$ $(17 \%)$ of patients from whom trichomonads could not be isolated had a similar titre. Whether these 26 cases represented past infections, or whether the microscopic diagnosis was incorrect, is not known, but complement-fixing antibodies can be detected after successful treatment (Beck et al., 1971). IgG antibodies rather than IgM were detected, and the role of IgM, which Chipperfield and Evans (1972) found in the endocervix of trichomoniasis patients, is uncertain.

The IFA test indicated that twice as many patients had antitrichomonal antibody as had microscopically proven infections. Taking the $1 / 4$ dilution as indicating active infection, however, $36.5 \%$ were serologically positive compared with $26 \%$ by microscopy. Previous studies have indicated that microscopy of cultures alone is not a reliable diagnostic technique and should be used in conjunction with other tests (Mason et al., 1976). It is not, however, in the diagnosis of active infection in women that serological tests for trichomoniasis are advantageous. Microscopic diagnosis in males is generally regarded as unreliable (Jirovec and Petrù, 1968), while untreated trichomoniasis in females tends to become chronic low-grade infection, with few organisms present.

Thus both males and females may be undiagnosed carriers of the parasite, and transmission to uninfected sexual partners is possible. It is in diagnosing these carriers that serological techniques may have their greater potential.

The help of the staff of the antenatal clinic, Harare Hospital, particularly Sisters Masvikeni and Garwe, is gratefully acknowledged.

\section{References}

Ackers, J. P., Lumsden, W. H. R., Catterall, R. D., and Coyle, R. (1975). Antitrichomonal antibody in the vaginal secretions of women infected with $T$. vaginalis. British Journal of Venereal Diseases, 51, 319-323.

Al-Salihi, F. L., Curran, J. P., and Wang, J. S. (1974). Neonatal Trichomonas vaginalis: Report of three cases and review of the literature. Paediatrics, 53, 196-200.

Beck, K. J., Saathoff, M., and Merkl, H. (1971). Vergleichende mikroskopische, kulturelle und serologische Untersuchungen auf Trichomonas vaginalis. Geburtshilfe und Frauenheilkunde, 31, 551-560. Abstracted in British Journal of Venereal Diseases, 48, 408 (1972).

Chipperfield, E. J., and Evans, B. A. (1972). The influence of local infection on immunoglobulin formation in the human endocervix. Clinical and Experimental Immunology, 11, 219-223.

Diamond, L. S. (1957). The establishment of various trichomonads of animals and man in axenic cultures. Journal of Parasitology, 43, 488-490.

Forgan, R. (1972). History of the treatment of trichomoniasis. British Journal of Venereal Diseases, 48, 522-524.

Heller, R. H., Joseph, J. M., and Davis, H. J. (1969). 
Vulvovaginitis in the premenarcheal child. Journal of Paediatrics, 74, 370-377.

Honigberg, B. M. (1972). Trichomonads. In Immunity to Parasitic Animals, edited by G. J. Jackson, R. Herman, and I. Singer, vol. 2, pp. 469-550. Appleton Century Crofts, New York.

Hughes, H. E., Gordon, A. M., and Barr, G. T. D. (1966). A clinical and laboratory study of trichomoniasis of the female genital tract. Journal of Obstetrics and Gynaecology of the British Commonwealth, 73, 821-827.

Jirovec, O., and Petrů, M. (1968). Trichomonas vaginalis and trichomoniasis. Advances in Parasitology, 6, 117-188.

Kramar, J., and Kucera, K. (1966). Immunofluorescence demonstration of antibodies in urogenital tricho- moniasis. Journal of Hygiene, Epidemiology, Microbiology and Immunology, 10, 85-88.

Mason, P. R., Super, H., and Fripp, P. J. (1976). Comparison of four techniques for the routine diagnosis of Trichomonas vaginalis infection. Journal of Clinical Pathology, 29, 154-157.

Powell, W. N. (1936). Trichomonas vaginalis Donné 1836: Its morphologic characteristics, mitosis and specific identity. American Journal of Hygiene, 24, 145-169.

Requests for reprints to: Dr P. R. Mason, Department of Medical Microbiology, PO Box MP 167, Mount Pleasant, Salisbury, Zimbabwe Rhodesia. 